\title{
SOFT LAW Y PAUTAS DE CONDUCTA EN MATERIA DE BIOÉTICA Y DERECHOS HUMANOS: SU INTEGRACIÓN EL SISTEMA JURÍDICO MEXICANO.
}

\section{SOFT LAW AND GUIDELINES OF CONDUCT IN THE FIELD OF BIOETHICS AND HUMAN RIGHTS: ITS INTEGRATION IN THE MEXICAN LEGAL SYSTEM}

Raúl RUIZ CANIZALES*

RESUMEN: El objetivo del presente artículo es describir la importancia que revisten, en el marco de la gobernanza, ciertos mecanismos internacionales de naturaleza soft law, así como las cuestiones de la vinculatoriedad entre la comunidad internacional y el proceso de integración en el sistema jurídico mexicano a partir de un par de criterios adoptados por la Suprema Corte de Justicia de la Nación. Mediante un análisis crítico del posicionamiento de la SCJN respecto de dichos instrumentos internacionales, el artículo también se centra en la trascendencia que éstos adquieren en la labor interpretativa de los órganos jurisdiccionales y otras autoridades a partir de la consideración de los núcleos semánticos que aquellos revisten (tales como 'dignidad', 'calidad de vida', etc.) que pueden derivarse de la misma actividad interpretativa en materia de Bioética y de derechos humanos.

ABSTRACT: The objective of this article is to describe the importance, in the framework of governance, of some international soft law mechanisms, as well as the issues of bindin legal force between the international community and the integration process in the Mexican legal system from a couple of criteria adopted by the Supreme Court of Justice of the

\footnotetext{
* Doctor en derecho y Docente investigador adscrito a la Facultad de Derecho de la Universidad Autónoma de Querétaro, Profesor de Tiempo Completo nivel VII. Correo electrónico: raul.canizales@ hotmail.com
} 
Nation. Through a critical analysis of the position of the SCJN with respect to these international instruments, the article also focuses on the importance they acquire in the interpretative work of the jurisdictional instituons and other authorities based on the consideration of the semantic nuclei they represent (such as 'dignity', 'quality of life', etc.) that can be derived from the same interpretive activity in the field of Bioethics and human rights.

Palabras clave: Bioética, gobernanza, soft law, derechos humanos.

Keywords: Bioethic, governance, soft law, human rights.

\section{Introducción}

El propósito del presente trabajo no es llevar a cabo un análisis de los derechos humanos ni mucho menos describir la confrontación entre las diversas posturas o las diversas ideologías que cohabitan en el discurso jurídico y que dan cuenta de aquéllos. En todo caso nos proponemos llevar a cabo algunas reflexiones sobre el estatuto jurídico que advierten algunos instrumentos del derecho internacional, específicamente las denominadas declaraciones y otras más, tales como los principios del derecho global y los propios de la bioética. Todo ello a partir del posicionamiento que acaba de asumir la Suprema Corte de Justicia de la Nación derivado de la reciente publicación de algunas tesis aisladas en la materia. El ángulo principal — pero no único — desde el cual compartiré estas reflexiones es desde la bioética, por ser este espacio inter y multidisciplinario el más prometedor y en donde mayormente se percibe una invocación de tales instrumentos. Por ello — debemos aclarar - tampoco es propósito de este ensayo exponer de manera extensa el estado del arte respecto de la jerarquía de los tratados internacionales de derechos humanos dentro del sistema jurídico mexicano. Habrá algunos asomos, pero en el núcleo central se encontrarán otras líneas de discusión. 
No está demás compartir que es en la bioética en donde se pone en juego un conjunto de elementos que convergen a fin de dar cuenta de las pautas de conducta que habrán de seguirse en experiencias tales como la investigación con seres humanos, Fecundación In Vitro (FIV), técnicas de reproducción asistida (TRA), aborto, eutanasia, medio ambiente, transgénicos, genoma humano, el uso de placebos, el caso de los medicamentos "huérfanos", calidad de vida, etc. A pesar del avance que se ha tenido en los sistemas jurídicos de otros países en materia de regulación de las pautas de conducta en la práctica médica y otras como las ya descritas, también es cierto que aún quedan fuertes dosis de incertidumbre entre los diferentes gremios de profesionales, pero principalmente entre médicos y abogados, científicos, etc.

La tarea aquí propuesta, entonces, se encamina a compartir una serie de reflexiones en torno al giro que han tomado - en el sistema jurídico mexicano- un tipo específico de instrumentos de orden internacional: las declaraciones de derechos humanos en general así como las declaraciones de derechos humanos en bioética.

\section{El contexto}

A partir del periodo de la posguerra la cultura constitucional en Occidente comienza a tomar un giro radical. Los procesos de Nüremberg marcaron un hito en la historia de la ética y la práctica médica o, mejor dicho, entre la ética y el quehacer científico-político. No hay que perder de vista que la herencia derivada del enfrentamiento bélico inspirado por los más diversos fundamentalismos puso en crisis el modelo legalista de la constitución conocido también como el modelo positivista, Estado legislativo o Estado derecho-, un paradigma que finalmente sucumbió a la marcada confrontación protagonizada por quienes veían en esa doctrina del culto a la ley una seria amenaza para aquellos que insistían en reinventar el derecho como instrumento de cohesión social. ${ }^{1}$

\footnotetext{
${ }^{1}$ Véase la interesante reflexión que hace Rodolfo Vázquez en torno al uso adecuado o no de la expresión "cambio de paradigma" cuando nos referimos a la reforma constitucional de 10 de junio de 2011 en materia
} 
A partir del periodo de la posguerra se inicia un largo y nada fácil trayecto hacia la modernización y humanización del derecho en el que las constituciones serían la piedra de toque de todas las culturas jurídicas. Aunado a lo anterior, en nuestras latitudes, es a partir de ese periodo de posguerra en el que se percibe un rol más central de las constituciones: el de la protección más amplia de los derechos humanos. Es así como surge una tendencia jurídica en la que convergen, en dichos documentos, tres factores principales:

a) El primero, se trata de una distribución más formal de poder entre los órganos estatales;

b) En segundo término, la inclusión de un conjunto de derechos fundamentales que vendrían a funcionar como una especie de barra de contención a la nueva forma de interpretación, la aplicación y producción legislativa: en términos postpositivistas o incluso visto desde el garantismo, ya no bastaría la simple atención a los lineamientos de producción normativa, $i$. e., a la validez procesal, sino que ahora habrá que atenderse el contenido de la norma misma para verificar su concordancia con el contenido sustantivo de las normas referidas a los derechos fundamentales, lo que significaría algo como una especie de validez sustantiva ${ }^{2}$;

c) En tercer lugar, se percibe también un proceso de incorporación de rigurosos y novedosos mecanismos de control constitucional de las leyes.

En otras palabras, lo anterior se traduce en un claro control mucho más riguroso hacia los poderes en cuanto a la producción, la aplicación, pero principalmente en cuanto al

de derechos humanos. La tesis que sostiene el autor es lo que estamos presenciando son los elementos de un Estado constitucional pospositivista de derecho. En otras palabras, no es un nuevo paradigma, sino una concepción más fortalecida y superadora del positivismo jurídico decimonónico (o paleopositivista), ambos pertenecientes al paradigma de la modernidad ilustrada. Vid. VÁZQUEZ, R., Derechos humanos. Una lectura liberal igualitaria, Ciudad de México, UNAM-ITAM, 2015, pp. xv y ss.

${ }^{2}$ Lo que implica la exigencia de que las de las normas incluyan también una grado de coherencia o sincronía entre sus contenidos o significados con los principios de carácter sustancial enunciados en la Constitución, tales como el principio de igualdad y los derechos fundamentales, además de que se debe admitir, por lo tanto, la posibilidad de normas formalmente vigentes y sin embargo sustancialmente inválidas. En otras palabras, “(...) un deber de conformidad y de coherencia de cara al legislador, so pena de la invalidez de sus productos normativos." Cfr. FERRAJOLI, L., El garantismo y la filosofía del derecho, traducción de Gerardo Pisarello, Alexei Julio Estrada y José Manuel Díaz Martín, Bogotá, Universidad Externado de Colombia, Serie de Teoría Jurídica y Filosofía del Derecho, No. 15, 2000 (primera reimpresión 2001), p. 58, nota 27. 
contenido. Es así como surge el denominado Estado Constitucional o Estado Constitucional Democrático de Derecho (o pospositivista de derecho). ¿De qué estamos hablando o frente a qué estamos colocados en el mundo jurídico occidental? ¿Cuáles son las aristas derivadas de ese nuevo esquema de protección de los gobernados? ¿Cuál es el campo de impacto que ha tenido ese diseño constitucional? Lo primero que nos atreveríamos a sostener es que se trata de un nuevo rostro del constitucionalismo occidental, de una nueva faceta o, si se quiere mencionarlo en estos términos, estamos colocados frente a una nueva fisonomía del orden político y del orden constitucional como una etapa de superación del arcaico estado de derecho o del viejo culto al Estado de derecho. La emergente cuestión social ahora exigía sistemas jurídicos más efectivos de control político, pero también de mayor control y vigilancia hacia los derechos fundamentales o derechos humanos, según se quiera ver.

La propia comunidad internacional, por su parte, requería avanzar más allá del esquema tradicional de medición de fuerzas, habría que dar paso a la posibilidad de un derecho cosmopolita, en los términos que ya planteados por I. Kant ${ }^{3}$, pero más allá de la idea de una federación de estados libres que contenga en su seno a todos los pueblos de la tierra o, para decirlo con Jürgen Habermas, más allá del contenido moral del derecho internacional clásico de tipo precario ${ }^{4}$.

Este es uno de los elementos en el que mayormente se enfocaría la doctrina constitucional de la posguerra. De ahí en adelante, poco a poco los derechos humanos ganaban terreno en los sistemas jurídicos. De hecho, en el nuevo Estado constitucional de la posguerra al mismo tiempo que convergen dos tipos de derechos o dos nuevos discursos (en términos de filosofía política y jurídica) gradualmente cobraron fuerza el discurso de los derechos humanos y el de los derechos sociales.

\footnotetext{
${ }^{3}$ KANT, I., La paz perpetua, trad. Susana Aguiar, Buenos Aires, edit., Longseller, 2001, p. 47.

${ }^{4}$ HABERMAS, J., El derecho internacional en la transición hacia un espacio posnacional, Madrid, Katz Editores, 2008, p. 13.
} 
IUS ET SCIENTIA (ISSN: 2444-8478) 2018, Vol. 4, nº 1, pp. 107-131

"Soft law y pautas de conducta en materia de bioética y derechos humanos: su integración el sistema jurídico mexicano".
Raúl RUIZ CANIZALES. Universidad Autónoma de Querétaro. raul.canizales@ hotmail.com
Enviado: 20/06/2018. Aceptado: 01/07/2018
DOI: http://dx.doi.org/10.12795/IETSCIENTIA.2018.i01.07

Instrumentos jurídicos vinculatorios: caracterización

\section{El derecho como sistema de normas vinculatorias}

En una determinada concepción del derecho y, en su sentido más amplio, también es descrito a éste como un complejo de normas e instituciones que imperan coactivamente en una comunidad estatal (como orden o sistema jurídico). De lo anterior compartimos que $a$ ) está compuesto por un conjunto de normas jurídicas (proposiciones prescriptivas) que contienen prohibiciones, imponen deberes y otorgan derechos y facultades con el propósito de estabilizar la intención de las conductas humanas, y en consecuencia constituyen las bases de convivencia social, además tiene como objetivo dotar a todos los miembros de la sociedad de los mínimos de seguridad, certeza, igualdad, libertad y justicia; y $b$ ) Utiliza un lenguaje particular: el lenguaje normativo. Este lenguaje normativo se halla directamente relacionado con la función que el Derecho desempeña, a saber, intenta regular ciertas manifestaciones de la conducta humana en sociedad; asimismo, este lenguaje normativo constituye, a su vez, el lenguaje prescriptivo, propiamente dicho. En este sentido, los rasgos distintivos del lenguaje prescriptivo es que 1) Las órdenes o directivas u oraciones directivas van dirigidas a influir en la conducta humana o por lo menos están enfocadas a eso, 2) El hecho de que logre o no su propósito no les quita tal carácter, en todo caso ese sería competencia de la sociología jurídica o, en su defecto, un asunto de eficacia normativa que compete a los productores de teoría del derecho (entre otros), y 3) No tiene sentido predicar sobre ellas su carácter de verdadero o falso, e incluso, para algunos, si son justas o injustas. Situación esta última que contrasta con el discurso iusfilosófico de los derechos humanos. 5

Ahora bien, si participamos de la tesis de que la ley es "norma jurídica que, con carácter general y obligatorio, resulta de un proceso específico de creación por parte del órgano o

\footnotetext{
${ }^{5}$ Para una mayor profundización véase TAMAYO Y SALMORÁN, R., Introducción analítica al estudio del derecho, Ciudad de México, editorial Themis, 2008, pp. 239-251.
} 
autoridad facultada al efecto."6, resulta entonces que de todas las características de la misma (abstracción, generalidad, obligatoriedad, irretroactividad y coercibilidad) es el rasgo de la coercitividad el que resulta constituirse como el definitorio de todo sistema normativo. La coercibilidad es una nota propia del derecho que, entre otras, lo distingue de la moral y de otros órdenes normativos. Empero, lo mismo que la obligatoriedad, la coercibilidad jurídica es especial. Aunque normalmente se diferencia entre un mandato y la observancia del mandato ${ }^{7}$, bajo el vocablo 'coercibilidad' se significa un mandato que puede ser impuesto aun en contra de la voluntad de los destinatarios (gobernados) o incluso de los gobernantes en el caso de normas específicas que los rigen. De ahí deriva la asociación entre la noción de carácter vinculatorio de las normas y el carácter coercible de las mismas. No obstante, cualesquier mandato de cualquier orden normativo puede, si se quiere, hacerse coercible aplicando para ello una fuerza o violencia física. Sin embargo, la violencia física (violencia legal como le han llamado en la sociología jurídica) de la que el derecho echa mano en los casos de incumplimiento, está legitimada, validada por el grupo social o por quienes detentan el poder. Lo mismo sucede con la vinculatoriedad. No existe el carácter vinculatorio de una norma si no existe la coercibilidad. Una deriva necesariamente de la otra. Aunque a veces no queda claro cuál es primero. Pues bien, esa coercibilidad o coacción constituye el instrumento para hacer efectiva una norma, sobre todo aquellas que contengan una sanción.

Pero resulta también que no todas las leyes están dotadas de una sanción o son diseñadas con el ánimo de disponer de una sanción (el caso de las llamadas leyes imperfectas), y por más que sean obligatorias no se puede castigar su incumplimiento. Además de que no es infrecuente esta circunstancia, se colige que es perfectamente explicable en los sistemas jurídicos. Esto puede tener dos orígenes:

\footnotetext{
${ }^{6}$ En este sentido véase ÁlvareZ, M., Conceptos jurídicos fundamentales, Ciudad de México, Mc Graw Hill, 2008, p. 40.

${ }^{7}$ Así, por ejemplo, KELSEN, H., Teoría general de las normas, trad. Hugo Carlos Delory Jacobs, Ciudad de México, D. F., editorial Trillas, 1994 (reimp. 2007), pp. 52-55.
} 
1. Error del legislador: se trata de una omisión de quien detenta la facultad de hacer leyes.

2. Derivado de la función misma de la norma: en virtud de que no todas ellas poseen un contenido material sancionable, una conducta, ya que

a. O rigen la producción de otras normas, su jerarquía o competencia;

b. O cumplen un papel interpretativo, programático, orientador o inspirador como el de los principios.

En estos últimos casos no es que el carácter vinculatorio no aplique, sino que está difuminado en la labor de significación de la norma.

Fuera de los casos anteriormente descritos, las sentencias o laudos, las resoluciones administrativas, los criterios jurisprudenciales de la Suprema Corte de Justicia de la Nación (entre otros) y, por tanto, de los tratados internacionales como un tipo de norma vinculante, no existe otro tipo de instrumentos que adviertan un carácter de tal naturaleza. ¿Qué pasa entonces con las simples declaraciones (o conferencias) de derechos humanos o con aquellos instrumentos que tienen como propósito normar la conducta de ciertos individuos en campos específicos como la práctica clínica, la investigación científica, investigación con seres humanos, etc.? La respuesta la compartirmos más adelante.

\section{El caso específico de los tratados internacionales en orden jurídico mexicano}

De acuerdo con el artículo 133 de la Constitución Política de los Estados Unidos Mexicanos, en el caso de los tratados internacionales, celebrados y que se celebren por el presidente de la República, con la aprobación del Senado serán, junto con la Constitución y las Leyes Federales, leyes supremas en toda la Unión.

De hecho, la Suprema Corte de Justicia de la Nación no siempre fue coherente en este tema específico, pues en un primer posicionamiento llegó a sostener que los tratados internacionales se encuentran en la misma jerarquía que las leyes federales y por debajo de 
la Constitución. ${ }^{8}$ En este sentido, la SCJN en el año de 1991 acotó respecto del tema que las leyes federales y los tratados internacionales tienen la misma jerarquía normativa, pero a pesar de que ambas tiene la misma jerarquía el tratado internacional no puede ser criterio para determinar la constitucionalidad de una ley ni viceversa. ${ }^{9}$

Más adelante, en el año de 1999 el criterio de la Suprema Corte de Justicia de la Nación cambió, pues ahora le otorga un papel de mayor jerarquía a los tratados internacionales pero sin estar a la par de la Constitución o norma fundante. En ese entonces determinó que los tratados internacionales se ubican jerárquicamente por encima de las leyes federales y en un segundo plano respecto de la constitución federal. ${ }^{10}$

Posteriormente, el día 13 de febrero de 2007, la misma Suprema Corte introduce una nueva modalidad al criterio antes sostenido sobre la jerarquía normativa constitucional, pues ahora distinguió dos tipos de niveles: en el primero de los niveles jerárquicos contempla un orden de carácter nacional, integrado sucesivamente por la Constitución Política de los Estados Unidos Mexicanos, tratados internacionales y leyes generales; un segundo nivel compuesto por leyes federales y locales. En ese criterio de la SCJN se precisa que las leyes generales o constitucionales son las expedidas por el Congreso de la Unión, para diferenciarlas de las emitidas por la Cámara de Diputados. Por último, se conserva en segundo orden — después de nuestra carta magna - a los tratados. En resumen, derivado de una nueva interpretación que hace del artículo 133 constitucional - y conforme a este nuevo criterio de la SCJNlos tratados internacionales son parte integrante de la ley suprema de la unión y se ubican jerárquicamente por encima de las leyes generales, federales y locales. ${ }^{11}$

\footnotetext{
${ }^{8}$ Semanario Judicial de la Federación, novena época, tomo XX, septiembre de 2004, p. 1896; Semanario Judicial de la Federación, novena época, tomo XXI, mayo de 2005, p. 1586.

${ }^{9}$ Amparo en revisión 2069/91. Registro: 205,596, tesis aislada, constitucional, octava época, pleno, Gaceta del Semanario Judicial de la Federación, t. 60, diciembre de 1992, tesis: P. C/92, p. 27.

${ }^{10}$ No. Registro: 192,867, Tesis aislada, Materia(s): Constitucional, Novena Época, Instancia: Pleno, Fuente: Semanario Judicial de la Federación y su Gaceta, X, Noviembre de 1999, Tesis: P. LXXVII/99, Página: 46.

${ }^{11}$ Parte del razonamiento fue el siguiente: "La interpretación sistemática del artículo 133 de la Constitución Política de los Estados Unidos Mexicanos permite identificar la existencia de un orden jurídico superior, de carácter nacional, integrado por la Constitución Federal, los tratados internacionales y las leyes generales. Asimismo, a partir de dicha interpretación, armonizada con los principios de derecho internacional dispersos en el texto constitucional, así como con las normas y premisas fundamentales de esa rama del derecho, se
} 
Sin embargo, a partir de la reforma al artículo $1^{\circ}$ de la CPEUM en junio de 2011 en materia de derechos humanos, los tratados internacionales tienen un papel preponderante en el sistema jurídico mexicano. Así lo determinó la SCJN en una tesis jurisprudencial en la que le agrega un nuevo valor al control de convencionalidad ex oficio en el modelo de control difuso de constitucionalidad. En dicho criterio desarrolla una interpretación avanzada de cara a los derechos humanos contemplados por vez primera en el texto constitucional. Sostiene ahora la SCJN que todas las autoridades del país, dentro del ámbito de sus competencias, se encuentran obligadas a velar no sólo por los derechos humanos contenidos en la Constitución Federal, sino también por aquellos contenidos en los instrumentos internacionales celebrados por el Estado Mexicano, adoptando la interpretación más favorable al derecho humano de que se trate, lo que se conoce en la doctrina como principio pro persona. Además de lo anterior, la SCJN agrega que dichos mandatos contenidos en el artículo 1o. constitucional deben interpretarse junto con lo establecido por el propio artículo 133 de la CPEUM a efecto de determinar el marco dentro del que debe realizarse el control de convencionalidad ex officio en materia de derechos humanos a cargo del Poder Judicial, el que deberá adecuarse al modelo de control de constitucionalidad existente en nuestro país. Sostiene en ese mismo criterio que, conforme a lo establecido en la última parte del artículo 133 constitucional, es en la función jurisdiccional en donde los jueces están obligados a preferir los derechos humanos contenidos en la Constitución y en los tratados internacionales, aun a pesar de las disposiciones en contrario que se encuentren en cualquier norma inferior. Por último, concluye la tesis jurisprudencial que si bien los jueces no pueden hacer una declaración

concluye que los tratados internacionales se ubican jerárquicamente abajo de la Constitución Federal y por encima de las leyes generales, federales y locales, en la medida en que el Estado Mexicano al suscribirlos, de conformidad con lo dispuesto en la Convención de Viena Sobre el Derecho de los Tratados entre los Estados y Organizaciones Internacionales o entre Organizaciones Internacionales y, además, atendiendo al principio fundamental de derecho internacional consuetudinario 'pacta sunt servanda', contrae libremente obligaciones frente a la comunidad internacional que no pueden ser desconocidas invocando normas de derecho interno y cuyo incumplimiento supone, por lo demás, una responsabilidad de carácter internacional." No. Registro: 172,650. Tesis aislada. Materia(s): Constitucional. Novena Época. Instancia: Pleno. Fuente: Semanario Judicial de la Federación y su Gaceta. XXV, Abril de 2007. Tesis: P. IX/2007, p. 6. 
general sobre la invalidez o expulsar del orden jurídico las normas que consideren contrarias a los derechos humanos contenidos en la Constitución y en los tratados sí están obligados a dejar de aplicar las normas inferiores dando preferencia a las contenidas en la Constitución y en los tratados en la materia. ${ }^{12}$

Lo que está en juego con esta tesis de la SCJN es el llamado "bloque de constitucionalidad". Eso por un lado, pero por otro, este primer criterio de la Suprema Corte en materia de derechos humanos no habla expresamente del asunto de la jerarquía de la que he venido compartiendo, pero sí se puede sostener que en ella subyace la idea de supremacía de los tratados internacionales en materia de derechos humanos respecto de las leyes federales y las locales, además de continuar con la línea de equiparación con la Constitución y, por tanto, queda incólume la naturaleza vinculatoria de los tratados o de cualquier otro instrumento, llámese como se llame, que haya sido suscrito por el ejecutivo y aprobado por el Senado de la República.

\section{La experiencia de otros instrumentos no vinculantes en bioética}

\section{Como criterios morales orientadores}

Existen otros instrumentos en materia de derechos humanos que si bien es cierto no tienen el carácter de tratado o convención ${ }^{13}$ son frecuentemente invocados tanto en la doctrina como en la práctica profesional con el propósito de generar algunas pautas de conducta, todas ellas derivadas principalmente (mas no exclusiva) de la práctica médica, la investigación con seres humanos, etc. De ahí la importancia que reviste este tema para los involucrados (o interesados) en la bioética. Estos instrumentos se han constituido como la materia prima en la literatura asociada a la bioética, pues en ellos se perfila un enorme conjunto de criterios éticos que tratan de servir como canales de orientación del quehacer

\footnotetext{
12 10a. Época; Pleno; S.J.F. y su Gaceta; Libro III, Diciembre de 2011, Tomo 1; Pág. 535.

${ }^{13} \mathrm{O}$ cualquier otra denominación, siempre y cuando haya sido aprobado por el Senado de la República.
} 
profesional en aquellas áreas. De manera enunciativa mencionamos los siguientes: 1. Código de Núremberg (1947); 2. Declaración de Helsinki (1964); 3. Consejo de Organizaciones Internacionales de las Ciencias Médicas (CIOMS) (1993); 4. Buenas Prácticas Clínicas (1996); 5. Declaración Universal sobre Bioética y Derechos Humanos (2005); 6. Declaración Universal de los Derechos Humanos, entre otros muchos. Se trata de instrumentos que al no poseer estatuto jurídico de tratado internacional carecen de fuerza vinculatoria, con el alcance que ya expliqué. En efecto,

"Los tratados internacionales vigentes y ratificados por los países, poseen idéntica jerarquía que las cartas constitucionales. No sucede igual cosa con una declaración bioética, cuya eficacia puede ser tan limitada como los contratos que debiendo ser escriturados, se acuerdan de palabra, y luego se incumplan vulnerando la buena fe."14

En otros términos, no reúnen las cualidades de todo sistema jurídico, las cuales podemos describir de la siguiente manera: ${ }^{15}$ a) Sistemas jurídico como sistemas normativos, $i$. $e$. como un sistema deductivo de enunciados, entendido éste último como un conjunto cualquiera de enunciados que comprende todas sus consecuencias lógicas, esto es lo que para un sector de la doctrina constituyen los elementos de configuran una 'norma'. Un sistema normativo es un sistema deductivo de enunciados entre cuyas consecuencias lógicas hay al menos una norma, $i$. e., un enunciado que correlaciona un caso determinado con una solución normativa (permisión, prohibición u obligatoriedad de cierta acción); b) Sistemas jurídicos como sistemas coactivos: prescriben sanciones; c) Sistemas jurídicos como sistemas institucionalizados: fuente de poder (soberano), i. e., se trata de aquellas instituciones creadoras y las aplicadoras del derecho.

\footnotetext{
${ }^{14}$ CORNEJO PLAZA, M. I., "Naturaleza jurídica de las declaraciones internacionales sobre bioética", [en línea] España, Universitat de Barcelona, 2015, Revista de Bioética y Derecho, núm. 34, 2015, p. 28.

${ }^{15}$ Para esta caracterización véase, NINO, C. S., Introducción al análisis del derecho, $2^{\mathrm{a}}$ ed. (14 ${ }^{\mathrm{a}}$ reimpresión), Buenos Aires, editorial Astrea, 2007, pp. 101-108.
} 
A partir de la anterior descripción surge la siguiente pregunta ¿por qué, entonces, ante temas tan complejos como los que suelen presentarse en la bioética se ha optado por la vía de las declaraciones y no directamente de los tratados? O en términos de Cornejo Plaza: ¿Por qué se eligió la Unesco la vía de la Declaración, que no es técnicamente vinculante, en lugar de la vía de la Convención, que sí lo es? No parece desatinada la respuesta que el embajador Gros Espiell ha dado a esta pregunta, pues consideramos que ha dado una explicación bastante sólida y pragmática acorde con lo que sucede en la vida real o en el proceso de "fecundación y gestación" de numerosos instrumentos internacionales. Él fue quien tuvo la oportunidad de presidir la misma Comisión Jurídica que redactó la Declaración Universal sobre el Genoma Humano y los Derechos Humanos. A partir de esa experiencia, justifica la vía de la declaración al recalcar la rapidez con que se puede aprobar un instrumento de esta naturaleza, contrario a la lo que normalmente sucede cuando se decanta por la vía de los tratados: la lentitud del procedimiento de ratificación de las Convenciones. Si hacemos una revisión de ello nos daremos cuenta de una cifra importante de instrumentos qua han sido gestados en sus inicios en la propia dimensión de las declaraciones; además, en este sentido, el embajador también agregó que una declaración deja siempre abierto el camino para una Convención posterior. ${ }^{16}$ Esta situación, más que inhibir la búsqueda de mejores y más eficaces instrumentos que normen las pautas de conducta en temas muy discutidos en la bioética, resulta a todas luces alentadoras.

En el caso de México, por ejemplo, la Suprema Corte ha emitido un criterio (tesis) que resulta por demás interesante, pues reafirma lo anteriormente compartido en materia de declaraciones y el estatuto jurídico que éstas revisten. La tesis contiene que la Declaración Universal de los Derechos Humanos, así como sus disposiciones, invocadas aisladamente, no pueden servir de parámetro para determinar la validez de las normas del orden jurídico mexicano, al no constituir un tratado internacional celebrado por el ejecutivo federal y

\footnotetext{
${ }^{16}$ GROSS SPIELL, H., "Más allá de la Declaración de la Unesco sobre el Genoma Humano y los Derechos Humanos", citado por Cornejo Plaza, María Isabel, op. cit., p. 33.
} 
aprobado por el senado de la república. La SCJN consideró que no obstante la importancia histórica y política que reviste la Declaración Universal de los Derechos Humanos, y no obstante que sus principios ya han sido fuente de inspiración e incorporados a tratados universales y regionales para la protección de los derechos humanos, concluye que las disposiciones de dicha Declaración, invocadas de manera aislada, no pueden servir de parámetro para determinar la validez de las normas del orden jurídico mexicano, al no constituir un tratado internacional celebrado por el titular del poder ejecutivo federal y aprobado por el Senado de la República en términos de los artículos 89, fracción X, y 76, fracción I, de la Constitución Federal. Concluye la SCJN que

“...lo anterior, sin perjuicio de que una norma internacional de derechos humanos vinculante para el Estado Mexicano pueda ser interpretada a la luz de los principios de la Declaración Universal de los Derechos Humanos, esto es, los principios consagrados en ésta pueden ser invocados por los tribunales para interpretar los derechos humanos reconocidos en los tratados internacionales incorporados a nuestro sistema jurídico. $^{17}$

Se pueden hacer muchas interpretaciones sobre las posibles implicaciones que este criterio o tesis aislada podría generar. Únicamente nos limitaremos a comentar que, en otras palabras, la idea que subyace en la parte última de la tesis es la de que los principios insertos en las declaraciones pueden servir como núcleos semánticos de interpretación de las proposiciones prescriptivas contenidas en los instrumentos que sí son vinculantes ${ }^{18}$. Esto marca un hito en la historia de la interpretación del derecho, puesto que en la tesis

\footnotetext{
${ }^{17}$ Época: Décima Época Registro: 2006533. Instancia: Primera Sala. Tipo de Tesis: Aislada. Fuente: Gaceta del Semanario Judicial de la Federación. Libro 6, Mayo de 2014, Tomo I. Materia(s): Constitucional Tesis: 1a. CXVI/2014 (10a.) Página: 539.

${ }^{18}$ KELSEN advierte que "(...) la declaración es el sentido de un acto de pensamiento, en tanto que la norma (...) es el sentido de un acto volitivo intencional y dirigido a un comportamiento humano específico.", Cfr. KELSEN, H., op. cit., p. 43. El sentido con el que usa Kelsen la expresión 'declaración' puede aplicarse también para el significado con el que en este trabajo se utiliza.
} 
citada se deja abierta la posibilidad de colocar a los principios éticos como poseedores de una capacidad ilustrativa, sobre todo cuando se trata de principios éticos que pretender normar o generar pautas de conducta en una multitud de áreas profesionales.

\section{Como instrumentos 'soft law'}

Como instrumentos o criterios regulatorios, si bien es cierto que poseen un grado de compromiso "normativo" (en el sentido no de obligar sino de normar éticamente la conducta), no son vinculantes en el sentido que ya explicamos y que están directamente vinculados a la idea de coacción en la expresión formal de un régimen de sanciones.

En el ámbito de la bioética y de la biotecnología han sido muchas las experiencias que han derivado en dilemas morales en los que la normatividad vigente a veces resulta obsoleta, de modo que los instrumentos de carácter moral - como las declaraciones en derechos humanos o en bioética o en ambos a la vez - puede acotar la acción de aquellos cuya práctica profesional podría poner en riesgo la propia vida o calidad de vida de los individuos.

La tecnociencia y la biotecnología han sido los protagonistas más importantes de este acelerado proceso de cambios, situación que evidenció la rapidez con la que muchas instituciones del derecho pueden quedar desfasadas. Uno de los ejemplos más ilustrativos es el caso de las figuras jurídicas de cuño romano, como por ejemplo la paternidad, maternidad y la filiación, las cuales dejaron de tener respuesta ante los avances de la biotecnología reproductiva, sobre todo si se tiene presente que nuestros códigos regularon por siglos esquemas normales de reproducción. Precisamente por ello el campo del derecho es donde mayor tarea y mayores retos se han presentado a la hora de tomar decisiones. En las últimas dos décadas el mundo jurídico occidental ha sido testigo y protagonista de importantes transformaciones en los sistemas jurídicos; todo apunta informar que la comunidad de actores y operadores del derecho han presenciado algo así como una especie de "giro constitucionalista", cuyo hilo conductor ha sido el discurso de los derechos 
humanos o los derecho fundamentales, así como los principios éticos y jurídicos (según el lente con el que se vea). La finalidad de ello ha sido transitar de poderes judiciales ausentes a tribunales constitucionales activos. Sin embargo, una de las manifestaciones o transformaciones dentro de los sistemas jurídicos que resulta de mayor importancia para efectos de este ensayo, consiste en algo que hemos optado por denominarle "hiperregulación”, lo que agravó aún más la crisis del modelo código, entendido como un medio para regular las relaciones entre sujetos jurídicos. Esta crisis tiene como referencia las serias críticas que desde comienzo del siglo XX se hiciera a dicho modelo, en la que podemos describir - entre otras y de manera general- las observaciones, procesos o fenómenos que la han acompañado: primero, el sistema legal que fue conformado por la constitucionalización de la segunda mitad del siglo XX es ahora despatrimonializado. Lo anterior significa una afectación, un trastocamiento de la concepción tradicional de los códigos civiles. Los derechos que tradicionalmente se habían reconocidos a los particulares ya no son los patrimoniales, tales como la propiedad, sino que ahora se reconocen derechos personales no sólo a nacionales sino a toda persona.

El segundo fenómeno — con un impacto negativo sobre el papel que venían desempeñando los códigos civiles - es de la descodificación. En efecto, una de las características de la época actual es, desde el punto de vista de la técnica legislativa, la denominada "edad de la decodificación": en ella el código civil pierde el carácter central del sistema jurídico, ya no es el principal instrumento legal de protección particular, ahora ese lugar lo ocupa las constituciones. Sumado a lo anterior, tendríamos que agregar que en este nuevo escenario tampoco el código civil sirve para proveer los principios generales, los cuales a menudo estaban previstos en microsistemas de leyes específicas con respecto a las categorías de bienes, de relaciones o de sujetos mismos. Así, como destino inevitable, los códigos, por el 
simple hecho de estar en el centro del sistema jurídico, terminaron por convertirse en una especie de derecho residual, en un tipo de normatividad anquilosada. ${ }^{19}$

En el caso de México, la Suprema Corte de México ha vuelto la vista a la noción de "soft law", lo que significa una especia de giro moral aplicado en virtud de que, por lo menos en materia de bioética, las declaraciones de este tipo son, ante todo, un conjunto de principios morales cuyo núcleo semántico, como también lo explicamos, sirve de barra de contención en la actividad interpretativa de las proposiciones prescriptivas.

No hay un consenso sobre cuál sería la definición más afortunada para el concepto 'soft law', sobre todo porque si revisamos la literatura al respecto nos podemos percatar que quienes han intentado formular una propuesta de definición caen en las telarañas del propio lenguaje. Desde nuestra perspectiva el problema reside en que al momento de desarrollar el concepto (definiendum), en la definición, es decir en el conjunto de términos que lo explican (definiens), siempre se echa mano de vocablos tales como 'reglas', 'normas', en incluso el propio término de 'derecho', etc., los cuales inducen a creer que con ellas se está haciendo referencia o se hace alusión a una entidad como perteneciente a un sistema jurídico cualquiera. De hecho, en la amplia plétora de definiciones elaboradas por diversos autores y que el propio Francisco L. Laporta nos comparte, es común encontrar en el definiens expresiones como "acuerdos de contenido preciso", "reglas de tratados", "normas de conducta", "normas internacionales", "normas de tipo no jurídico", "reglas de conducta", "obligaciones jurídicas", etc. ${ }^{20}$ Lo que genera dicha confusión es que tales expresiones son usadas de modo heterogéneo. Contrario a lo que cree Francisco J. Laporta, nosotros por nuestra parte sostenemos que el soft law no es parte de sistema normativo jurídico alguno, aunque sean aprobados, en el caso que nos interesa, en el propio seno de la

${ }^{19}$ Cfr. CIPPITANI, R., Construcción del derecho privado en la Unión Europea. Sujetos y relaciones jurídicas, Lisboa, edit. Juruá, 2017, pp. 43-47. La expresión "edad de la decodificación" la toma R. Cippitani de IRTI, N., L'etá della decodificazione, Milano, edit. Giuffré, 1999, p. 33.

${ }^{20}$ LAPORTA, F. L., "Gobernanza y soft law: nuevos perfiles jurídicos de la sociedad internacional”, en Ruiz Miguel, Alfonso (ed.). Entre Estado y cosmópolis. Derecho y justicia en un mundo global, Madrid, edit. Trotta, 2014, pp. 61 y ss. 
ONU. Si acaso forman parte de la jerga de la comunidad de individuos y de naciones, pero no se verifica en ellos el criterio de pertenencia a sistema jurídico como el mexicano.

La aparición de los mecanismos o instrumentos soft law está asociado a aquellos vertiginosos cambios - descritos en párrafos anteriores - que han regido el estatuto epistemológico de las sociedades, pero sobre todo a las nuevas transformaciones y nuevos escenarios globales complejos que ha fomentado la generación de un derecho mucho más cosmopolita que, en términos de J. Habermas - en una interpretación que hace de I. Kant-, tiene como propósito la completa constitucionalización del derecho internacional en el marco de una república mundial fundada en los derechos humanos y de los ciudadanos. ${ }^{21}$ Estos nuevos escenarios sociales, políticos, culturales y económicos llevan en su seno la proliferación de relaciones cada vez más complejas, pero también llevan consigo la exigencia de nuevos formas de afrontar las diferencias. No es que los mecanismos vinculatorios tradicionales del derecho internacional (tratados, convenciones, etc.) estén agotados — nada más fuera de la realidad - sino que en todo caso lo que pretendemos justificar es que al lado de esos históricos instrumentos vinculantes internacionales se puede echar mano de un tipo de instrumentos que obedecen a tales circunstancias complejas, pero que lejos de apostarle a la fuerza coactiva que los acompaña la apuesta va por el peso moral del que están revestidos o, para decirlo con Francisco L. Laporta, apostarle a un derecho transfronterizo, a un derecho nuevo de regular esas interacciones contemporáneas ante la ausencia de gobiernos competentes, de normas jurídicas adecuadas o cuando no se da la posibilidad remota de acudir al respaldo coactivo para garantizar el cumplimiento de norma alguna. De hecho,

"Lo que parece que entonces nos piden estas nuevas realidades es ir a la búsqueda de nuevos conceptos políticos y jurídicos capaces de describir con acuidad la nueva situación. En eso consiste el gran debate sobre la

\footnotetext{
${ }^{21}$ HABERMAS, J. El derecho internacional en la transición hacia un espacio posnacional, op. cit., p. 15.
} 
globalización cuando se lo mira desde la perspectiva de la teoría del

Derecho." $^{, 22}$

Por otra parte, en las últimas décadas el soft law también está íntimamente asociado al concepto de 'gobernanza', pero no a cualquiera de sus significados, sino que el alcance de gobernanza que interesa es aquel que abraza los siguientes cuatro elementos: ${ }^{23}$ primero, el que respecta a los actores en presencia: se refiere a un estado de cosas en el que participa una compleja pluralidad de actores, tanto públicos (en el nivel local, regional, etc.) como privados, instituciones, corporaciones, tercer sector, ONG (también de tipo multinivel). En otras palabras, este elemento hace alusión a la pluralidad y la complejidad de los actores presentes. El segundo elemento se refiere a las relaciones que se dan entre esos actores múltiples en las situaciones de gobernanza: una característica de este elemento es la ausencia de relaciones de jerarquía en sentido estricto. Los actores son interdependientes sin que predomine un diseño de jerarquía ni de hegemonía, pero tampoco implica actores plenamente autónomos e interdependientes relacionados desde la mera interdependencia, tal como sucede en las relaciones de mercado. El tercer elemento se refiere a las acciones de gobernanza: aquí se insiste en la autoorganización de las redes, las cuales fomentan pautas de comportamiento a partir de sí mismas, $i$ e., pautas que ha de tenerse siempre presentes al momento de articulación de los actos de gobernanza. Por otro lado también se insiste en la actividad de coordinación, guía, pilotaje, dirección, (steering/to steer), como contrapartida de la vieja idea del gobernante como piloto de la nave del Estado y que para ello echa mano de medidas coactivas. Se trata, en todo caso, de encauzar y coordinas las diferentes fuerzas derivado de los diversos actores, sin que lo anterior autorice a afirmar que el gobierno o el Estado poseen una fuerza superior que les permita imponer sus políticas. No implica regular, sino gestionar las reglas que pueden surgir, aunque también puede implicar negociar la generación de esas reglas. El cuarto y último elemento tiene que

\footnotetext{
${ }^{22}$ LAPORTA, F. L., "Gobernanza y soft law: nuevos perfiles jurídicos de la sociedad internacional”, op. cit., p. 42.

${ }^{23}$ Ídem, pp. 58 y 59.
} 
ver con la naturaleza de las pautas que surgen de las actividades de gobernanza: en este sentido, se trata de regulaciones que se asientan sobre la flexibilidad y la permisividad, en el sentido de que muchas veces se presentan para ser seguidas, pero siempre y cuando no pueda aducirse alguna razón en contra de ellas que las supere, y pueden en todo caso ser discutidas.

Lo que es un hecho, entonces, es que el soft law está sujeto a la idea de gobernanza, mientras que el hard law está vinculado directamente a la idea de gobierno: gobernanzasoft law/gobierno o gobernabilidad. En efecto:

"En sistemas de gobierno el Derecho es duro (hard); en sistemas de gobernanza el derecho es blando (soft). La diferencia crucial entre estos dos tipos de normas jurídicas es que el soft law carece de posibilidad de sanciones legales. Es decir, que el soft law no se considera legalmente vinculante [...] gobierno es a derecho duro, lo que gobernanza es a derecho blando o suave." 24

La tesis que recientemente ha sido adoptada por el alto tribunal de México (marzo del 2015) plantea lo siguientes. Primero, sostiene la SCJN que de conformidad con el artículo 10. de la CPEUM y su alcance protector en materia de derechos humanos, todos los agentes del Estado mexicano no sólo deben observar la normativa internacional de carácter obligatorio y la jurisprudencia interamericana, sino que en virtud de las máximas de universalidad y progresividad que también contempla, debe admitirse el desarrollo de principios y prácticas del derecho internacional de carácter no vinculante previstos en instrumentos, declaraciones, proclamas, normas uniformes, directrices y recomendaciones aceptados por la mayoría de los Estados.

En esa misma resolución de marzo de 2015 la SCJN explica que dichos principios son identificados por la doctrina como "soft law", cuya traducción corresponde a "ley suave",

\footnotetext{
24 Ídem, p. 60.
} 
normas ligeras, dúctiles o blandas y es empleado dado 1) el sentido de falta de eficacia obligatoria y 2) en oposición al "hard law" o derecho duro o positivo. Pero para nuestro alto tribunal, independientemente de la obligatoriedad que revistan, el contenido del soft law puede ser útil para que los Estados, en lo individual, guíen la práctica y mejoramiento de sus instituciones encargadas de vigilar, promover y garantizar el apego irrestricto a los derechos humanos. No obstante, concluye la resolución de la SCJN,

“... sin que ello implique desconocer la observancia primigenia del orden jurídico nacional, ni el principio de subsidiariedad de las normas supranacionales, según el cual, la protección internacional de los derechos humanos es aplicable después de agotada la tutela interna y, sólo en su defecto, debe acudirse a aquélla, pues más allá de que la Constitución Federal y los tratados no se relacionen en términos jerárquicos [...] la consulta de directrices no vinculantes sólo reporta efectos prácticos derivados de la experiencia acogida por órganos internacionales encargados de la promoción y protección de los derechos fundamentales.",25

Derivado de lo anterior, y para los propósitos de este ensayo, proponemos definir al soft law como un conjunto de instrumentos o mecanismos de la comunidad formal internacional de contenido moral (principios morales) cuyo campo semántico puede servir para la interpretación del hard law con efectos jurídicos directos e indirectos. Son instrumentos que se sitúan más en el campo de la ética que en el de los sistemas normativos. La apuesta sería — como la propia UNESCO lo ha manifestado- a maximizar la evolución moral y reducir

25 “'SOFT LAW'. LOS CRITERIOS Y DIRECTRICES DESARROLLADOS POR ÓRGANOS INTERNACIONALES ENCARGADOS DE LA PROMOCIÓN Y PROTECCIÓN DE LOS DERECHOS FUNDAMENTALES SON ÚTILES PARA QUE LOS ESTADOS, EN LO INDIVIDUAL, GUÍEN LA PRÁCTICA Y MEJORAMIENTO DE SUS INSTITUCIONES ENCARGADAS DE VIGILAR, PROMOVER Y GARANTIZAR EL APEGO IRRESTRICTO A LOS DERECHOS HUMANOS. Época: Décima Época. Registro: 2008663. Instancia: Tribunales Colegiados de Circuito. Tipo de Tesis: Aislada. Fuente: Semanario Judicial de la Federación. Publicación: viernes 13 de marzo de 2015 09:00 h. Materia(s): (Constitucional). Tesis: XXVII.3o.6 CS (10a.) 
al mínimo la necesidad de legislación tanto nacional como internacional, pues con el soft law no se aconseja nada a nadie, se le recuerda un deber. ${ }^{26}$ Visto así, debe dejarse claro que la propuesta que se abandera es que el derecho debe abrirse a otras posibilidades lógicas de resolución de conflictos. Debe abrirse a la posibilidad de otros esquemas de razonamientos. Un caso específico de vital importancia es la propia Declaración Universal sobre Bioética y Derecho Humanos, aprobada en el año 2005. Resulta de tal magnitud la trascendencia de este instrumentos de naturaleza 'soft-law' en virtud de la gran cantidad de ocasiones que se menciona (o se invoca) la palabra 'dignidad', en su faceta de principio.

"Y si bien los principios son guías y directrices que en sí mismas llevan envuelta una indeterminación, pueden llegar a ser causa y fundamento de una norma, entendiendo a esta como una regulación acabada y definida, circunscrita en su aplicación, tanto de manera internacional a través de un tratado, convención o declaración, o bien modelando las normativa interna de los países, entendiendo siempre que este proceso debe ser bajo los criterios del derecho internacional de los derechos humanos.",27

En otras palabras, el desarrollo de los principios contenidos en este tipo de declaraciones ${ }^{28}$ permite que éstos pueden utilizarse como una especie de guías cuyo núcleo semántico serviría para 'ilustrar' a cualquier clase de operador jurídico en caso de que la normativa interna e internacional en cuestión advierta problemas en su interpretación o, mejor dicho, cuando su núcleo semántico de la norma interna requiera ser alimentado por otro núcleo cuya morada es una declaración de tipo soft-law. Dichos núcleos semánticos son los típicamente invocados en la bioética: dignidad, calidad de vida, entre otros. Lo anterior nos

\footnotetext{
${ }^{26}$ LAPORTA, F., L. “Gobernanza y soft law: nuevos perfiles jurídicos de la sociedad internacional”, op. cit., p. 73.

${ }^{27}$ CORNEJO PLAZA, M. I., "Naturaleza jurídica de las declaraciones internacionales sobre bioética", op. cit., pp. 34 y 35.

${ }^{28}$ BAHRI, S. "Introducción a la Declaración Universal sobre Bioética y Derechos Humanos", en CASADO, M. (coord.). Sobre la dignidad y los principios. Análisis de la Declaración Universal sobre Bioética y Derechos Humanos de la UNESCO, España, edit. Aranzadi, 2009, p. 563.
} 
invita, entonces, a volver la vista hacia la eficacia jurídica interna, y no precisamente a la idea de un valor jurídico de carácter general.

\section{Conclusiones}

A medida que las sociedades evolucionan, y a medida que éstas quedan insertas dentro del radio de impacto de tales transformaciones, entonces las exigencias nuevas no se hacen esperar, de modo tal que el derecho o, mejor dicho, los sistemas jurídicos disminuyen su potencial de previsión y su capacidad de resolución, sobre todo en el caso en que esos sistemas jurídicos continúan operando con esquemas o figuras procesales que ante esas nuevas realidades se antojan como anquilosadas.

No suena exagerado sostener que el derecho internacional blando está adquiriendo una importancia similar que la adjudicada al derecho duro y que una gran parte de las relaciones internacionales se rige por este tipo de figuras. Sobre la pregunta respecto de cómo o en qué medida podríamos sostener que el soft law pertenece a los sistemas jurídicos es, ante todo, una prometedora y compleja discusión que se antoja, por lo menos, bastante concurrida.

Por lo pronto, si de lo que se trata es de subrayar la importancia de la eficacia jurídica interna, entonces la trascendencia de los núcleos semánticos de los conceptos que abanderan ciertos instrumentos como la Declaración Universal sobre Bioética y Derechos Humanos es de tal envergadura que se erigen en nichos de significación, por lo menos en sus alcances esenciales. 


\section{Bibliografía}

ÁLVAREZ, M. I., Conceptos jurídicos fundamentales, Ciudad de México, Mc Graw Hill, 2008.

BAHRI, S. "Introducción a la Declaración Universal sobre Bioética y Derechos Humanos”, en CASADO, M. (coord.). Sobre la dignidad y los principios. Análisis de la Declaración Universal sobre Bioética y Derechos Humanos de la UNESCO, España, edit. Aranzadi, 2009

CIPPITANI, R., Construcción del derecho privado en la Unión Europea. Sujetos y relaciones jurídicas, Lisboa, edit. Juruá, 2017.

CORNEJO PLAZA, M. I., "Naturaleza jurídica de las declaraciones internacionales sobre bioética", [en línea] España, Universitat de Barcelona, 2015, Revista de Bioética y Derecho, núm. 34, 2015.

FERRAJOLI, L., El garantismo y la filosofía del derecho, traducción de Gerardo Pisarello, Alexei Julio Estrada y José Manuel Díaz Martín, Bogotá, Universidad Externado de Colombia, Serie de Teoría Jurídica y Filosofía del Derecho, No. 15, 2000 (primera reimpresión, 2001).

HABERMAS, J., El derecho internacional en la transición hacia un espacio posnacional, Madrid, Katz Editores, 2008, p. 13.

KANT, I., La paz perpetua, trad. Susana Aguiar, Buenos Aires, edit., Longseller, 2001.

KELSEN, H., Teoría general de las normas, trad. Hugo Carlos Delory Jacobs, Ciudad de México, editorial Trillas, 1994 (reimp. 2007).

LAPORTA, F. L., "Gobernanza y soft law: nuevos perfiles jurídicos de la sociedad internacional", en RUIZ MIGUEL, A. (ed.), Entre Estado y cosmópolis. Derecho y justicia en un mundo global, Madrid, edit. Trotta, 2014.

NINO, C. S., Introducción al análisis del derecho, $2^{\mathrm{a}}$ ed. (14ª reimpresión), Buenos Aires, editorial Astrea, 2007. 
IUS ET SCIENTIA (ISSN: 2444-8478) 2018, Vol. 4, nº 1, pp. 107-131

"Soft law y pautas de conducta en materia de bioética y derechos humanos: su integración el sistema jurídico mexicano".

Raúl RUIZ CANIZALES. Universidad Autónoma de Querétaro. raul.canizales@ @otmail.com

Enviado: 20/06/2018. Aceptado: 01/07/2018

DOI: http://dx.doi.org/10.12795/IETSCIENTIA.2018.i01.07

TAMAYO Y SALMORÁN, R. Introducción analítica al estudio del derecho, Ciudad de México, editorial Themis, 2008.

VÁZQUEZ, R., Derechos humanos. Una lectura liberal igualitaria, Ciudad de México, UNAM-ITAM, 2015. 